\title{
Comparison of efficacy of laser lithotripter with ultrasonic lithotripter in mini percutaneous nephrolithotomy
}

\author{
Fatih Akbulut, Onur Kucuktopcu, Emre Kandemir, Erkan Sonmezay, Abdulmuttalip Simsek, \\ Burak Ucpinar, Faruk Ozgor, Gokhan Gurbuz \\ Department of Urology, Haseki Training and Research Hospital, Istanbul, Turkey.
}

\begin{abstract}
Summary Objective: The aim of the study was to compare the efficacy of the laser lithotripter with the ultrasonic lithotripter in mini percutaneous nephrolithotomy (miniperc).

Material and Methods: From June 2013 to January 2014; medical records of 77 consecutive patients who underwent miniperc operation were retrospectively evaluated. Ultrasonic lithotripter was used in 22 patients (Group 1), while laser was used in 55 patients. In the laser group, 22 patients were randomly selected who had same characteristics compared to group 1 (Group 2). Success rate, total operative time, complications according to modified Clavien classification, fluoroscopy time, haemoglobin drop, hospital stays and cost analysis were assessed. Success rates were evaluated on the second postoperative day and after the first month.

Results: Total operative time ( $p=0.635)$ and fluoroscopy time ( $p=0.248$ ) were not significantly different between the two groups. In the laser group, the success rate (81.8\%) was notably more than in the ultrasonic lithotripter group $(68.2 \%)$ but there was no statistically significance $(p=0.296)$. Ten reusable ultrasonic probe were used for 22 patients, due to thinness and sensitiveness of the probe. Conversely, one single laser fiber (550 micron) was used for 22 patients. When the cost analysis of lithotripsy was considered, the cost per case was 190 dollar in group 1 and 124 dollar in group 2. ( $p=0.154)$ Complication rate, hospital stay and haemoglobin drop were similar in both groups. Conclusion: Laser lithotripsy seems to be more cost effective than ultrasonic lithotripsy for miniperc but larger number of patients are required to confirm this estimation.
\end{abstract}

KEY WORDS: Laser lithotripsy; Ultrasonic lithotripsy; Mini percutaneous nephrolithotomy.

Submitted 30 May 2015; Accepted 4 July 2015

\section{INTRODUCTION}

Percutaneous nephrolithotomy (PNL) is the primary recommended treatment modality for the kidney stones larger than $2 \mathrm{~cm}$ and an optional treatment choice for stones between 1 and $2 \mathrm{~cm}$ (1). Even though PNL is a safe method with high stone clearance rate, it has serious complications like hemorrhage requiring transfusion and kidney loss. In order to reduce these complications, miniPNL (miniperc) was first described in pediatric popula- tion (2). In the following years, Jackman et al. used this technique in adult patients (3). Recently published studies underlined that complications like bleeding have declined along with the use of smaller renal access sheaths $(4,5)$. In a prospective randomized study, the authors suggested that while miniperc and conventional PNL had similar stone clearance rates, complication rate was significantly lower in the miniperc group (6).

In the miniperc series, the lithotripter choice is important for stone fragmentation. Laser, pneumatic, and ultrasonic lithotripters are available fragmentation methods for PNL. While pneumatic lithotripsy is the most common technique used for kidney or ureteral stones, stone retropulsion and migration rate is clearly higher compared with other devices. Ganeasomoni et al. compared laser and pneumatic lithotripsy with miniperc and observed that laser lithotripsy group had a lower stone migration rate (7). The ultrasonic lithotripsy enables simultaneous stone fragmentation and aspiration. Low retropulsion rate and absence of the need of stone retrieval are the main advantages of ultrasonic lithotripsy. However, to the best of our knowledge, there is no published study evaluating the efficacy of the ultrasonic lithotripter with miniperc. In this study, we aimed to compare laser lithotripter and ultrasonic lithotripter with miniperc for the treatment of kidney stones.

\section{MATERIALS AND METHODS}

From June 2013 to January 2014, medical records of 77 consecutive patients with kidney stones treated with miniperc were retrospectively evaluated. Patients were classified according to the lithotripter type used during the procedure. Ultrasonic lithotripter was used in 22 patients (group-1). Ho:YAG laser lithotripter was used in 55 patients and 22 of them (group-2) were matched to the group-1 based on the size, area, and localization of the stone. Informed consent was taken from all patients in the study. Patient demographics, operative parameters (operation time, fluoroscopy time, and cost), and post-operative parameters (hemoglobin drop, hospitalization time, and success and complications rates) were evaluated. All patients were evaluated with kidney, ureter, and bladder plain radiography (KUB), intravenous urography, and/or computed tomography (CT) preoperatively. 
The patients were assessed with complete blood count, serum biochemistry, coagulation parameters, and urine cultures before the operation.

\section{Miniperc technique}

All procedures were performed by the same experienced surgical team (FA and GG). Under general anesthesia, a 5 Fr ureteral catheter was placed into the ureter in lithotomy position, and the bladder was drained with a $16 \mathrm{Fr}$ Foley catheter. Percutaneous renal access was performed in prone position, under fluoroscopic guidance using an $18 \mathrm{G}$ access needle. A guidewire with hydrophilic tip was inserted into the collecting system through the access needle. Tract dilatation was carried out by either Amplatz or balloon dilatators up to 18-20 Fr. Stone fragmentation were performed by using Ho:YAG laser probe (Sphinx 30, Lisa Laser, USA) or ultrasonic lithotripter (Swiss LithoClast, EMS, Nyon, Switzerland) and stone fragments were removed with retrieval graspers through a 17 Fr nephroscope (Karl Storz, Tuttlingen, Germany). A 550-micron laser probe was used with energy and frequency settings of 1.5 joule and 10 to 20 , respectively.

The ultrasonic lithotripsy was performed with a 6 Fr ultrasonic probe. The flexible nephroscope was used with laser and nitinol basket catheter in situations where the rigid nephroscope couldn't reach the calyces or stones. Operations were terminated when no residual stone fragments could be detected with the help of rigid and/or flexible nephroscope and fluoroscopy. After completion of the operation, a 14-Fr nephrostomy tube was inserted in all patients.

Nephrostomy tubes were removed in post-operative $1^{\text {st }}$ or $2^{\text {nd }}$ days. All patients were initially evaluated with KUB in post-operative day one.

One month later, patients were reevaluated with KUB or CT. CT was performed when non-opaque stones were present or when evaluation of the stone status was insufficient with KUB. Residual fragments smaller than $3 \mathrm{~mm}$ were defined as clinically insignificant residual fragments (CIRF) (8). Larger stones were defined as residual stones. Patients who were completely stone free or who had only CIRF were considered to have had a successful surgery. Success rates at first day and at first month were given separately. Post-operative complications were classified according to the modified Clavien Classification system

\section{Cost analysis}

The total cost per patient was calculated as the sum of hospitalization, surgery, and broken probes costs. When a second intervention or hospitalization was needed, these costs were also added to the sum. Costs per patient were compared between the groups.

\section{Statistical analysis}

Statistical analyses were performed with the computer software Statistical Package for the Social Sciences (SPSS, IBM Software) V. 16.0.

Values were described as numbers, percentages, means, and standard deviations. Categorical and continuous variables were compared using chi square and Student ttests. $\mathrm{P}$ values less than 0.05 were considered as statistically significant.

\section{RESULTS}

Patients' data with regard to location, size and number of stones, age, gender, body mass index (BMI) and access location were reported in Table 1. Total operative time $(\mathrm{p}=0.635)$ and fluoroscopy time $(\mathrm{p}=0.248)$ were not significantly different between two groups. In the laser group, the stone clearance rate (81.8\%) was notably higher than in ultrasonic lithotripter group (68.2\%) at post-operative $1^{\text {st }}$ day according to KUB, although the difference was not statistically significant $(p=0.296)$. At post-operative first month, none of the patients had spontaneous passage of residual stones. Nine of reusable ultrasonic probes were broken, thus 10 reusable ultrasonic probes were used in 22 patients, due to fragility of the probe. Conversely, only one reusable laser probe (550 micron) was used in 22 patients. When the cost analysis of lithotripters was considered, the cost/per case was 190 dollar in-group 1 and 124 dollar in-group 2 $(\mathrm{p}=0,597)$. Complication rate, hospital stay and hemoglobin drop were similar in both groups (Table 2).

\section{Table 1.}

Preoperative patient demographics.

\begin{tabular}{lccc}
\hline & Laser & Ultrasonic & P value \\
\hline Number of patients & 22 & 22 & \\
\hline Gender & & & \\
\hline Male & 14 & 15 & 0.750 \\
\hline Female & 8 & 7 & \\
\hline Mean body mass index $\left(\mathrm{kg} / \mathrm{m}^{2}\right)$ & $26.2 \pm 3.6$ & $25.1 \pm 9.3$ & 0.584 \\
\hline Mean age (years) & $44.4 \pm 12.6$ & $40.6 \pm 14.8$ & 0.385 \\
\hline Mean stone size $(\mathrm{mm})$ & $21.14 \pm 8.5$ & $21.55 \pm 6.0$ & 0.855 \\
\hline Stone localization & & & 0.380 \\
\hline Upper pole & 0 & 2 & \\
\hline Middle calyx & 2 & 1 & \\
\hline Lower pole & 6 & 4 & \\
\hline Pelvis & 2 & 5 & \\
\hline Multiple calyceal & 12 & 10 & \\
\hline Access site & & & 0.295 \\
\hline Upper pole & 0 & 2 & \\
\hline Middle calyceal & 2 & 3 & \\
\hline Lower pole & 20 & 17 & \\
\hline
\end{tabular}

Table 2.

Comparison of postoperative parameters between laser lithotripsy and ultrasonic lithotripsy groups

\begin{tabular}{|lccc|}
\hline & Laser & Ultrasonic & P value \\
\hline Hemoglobin drop (mg/dl) & $0.93 \pm 1$ & $1.15 \pm 1,15$ & 0.520 \\
\hline Success rate at post operative first day (\%) & $81.8 \%$ & $68.2 \%$ & 0.296 \\
\hline $\begin{array}{l}\text { Success rate at post operative } \\
\text { first month imaging (\%) }\end{array}$ & $81.8 \%$ & $68.2 \%$ & 0.296 \\
\hline Hospitalization time (hours) & $74.2 \pm 22.1$ & $79.6 \pm 38.7$ & 0.569 \\
\hline Clavien complications & & & 0,304 \\
\hline 2 & 2 & 0 & \\
\hline 3A & 5 & 4 & \\
\hline Mean operation time (minutes) & $113.5 \pm 50.5$ & $107 \pm 34.9$ & 0.635 \\
\hline Mean fluoroscopy time (minutes) & $7.7 \pm 4.6$ & $6 \pm 4.5$ & 0.248 \\
\hline Mean cost per case (US Dollar) & 124 & 190 & 0.597 \\
\hline
\end{tabular}




\section{Discussion}

Percutaneous nephrolithotomy is a commonly and successfully performed surgical treatment option for large and complex renal stones. However in standard PNL series, there are non-negligible complications like bleeding, which may happen during and/or after the operation. Because of these complications, smaller access sheaths and instruments have increasingly been used since 1998 (3). According to these advancements, miniperc surgery is an alternative option to retrograde intrarenal surgery (RIRS) for management of small renal stones (9). In the miniperc surgery, laser and pneumatic lithotripters have been used for fragmentation of stones (7). However, there is no study in the literature, which shows the advantages/disadvantages of ultrasonic lithotripters in miniperc surgery. Utilization of the suitable lithotripter is important, because migration rates and operation times may vary in different lithotripter types.

With holmium: YAG laser, achievement of the stone fragmentation is achieved by phototermal effect. We used the laser at lower energy and high frequency setting to disintegrate the stone into smaller fragments and prevent the migration of the stone into different calyces or the ureter. If the energy is increased, the operation time decreases, but the rates of retropulsion of the stones tend to be higher (10) and larger stone fragments are produced (11). The ability of fragmenting all hard types of calculi such as calcium oxalate monohydrate and cystine stones is the most important advantage of the holmium: YAG laser (12). Despite this, the fragmentation time can be longer in the management of larger renal calculi.

The ultrasonic lithotripter has been widely used in standard PNL up to now. In this lithotripter, it is used mechanical energy that is produced by piezo-ceramic elements. The mechanical energy conveys through the probes to the stone with a drilling effect. The ultrasonic probe performs both stone fragmentation and stone particle aspiration simultaneously $(13,14)$. In the literature, the stone free rates were up to $97 \%$ in standard PNL series (15). However, the success rate with miniperc is lower, mainly because a thinner diameter probe has to be used. In this context, in our series with miniperc the stone free rate was $68.2 \%$ which was lower compared with the standard PNL series. Even though ultrasonic lithotripter has high success rates in the literature, the achievement of fragmentation declines when used for hard stones, such as calcium oxalate monohydrate and cystine stones (16).

In the ultrasonic lithotripter, the probe has potential overheating effect because of conversion of vibration energy to heat energy. This undesired effect may lead to tissue injury. In an experimental study, Diri et al. showed that ultrasonic probes may cause tissue injury in rat models (17). Furthermore, the overheating effect may lead to the breakage of the thin and fragile ultrasonic probe. In our series, we have used 10 reusable ultrasonic probes for 22 patients. For this reason, the costs of the operation were higher in-group 1. Conversely, in group 2 we used only one reusable 550 micron laser probe for 22 patients. Cost per case was notably lower (190 dollar/case in group 1, 124 dollar/case in-group 2) but the difference was not statistically significant. In larger patient series, the cost analyses could reveal more statistically significant differences. Notably, the 550-micron reusable laser probe is guaranteed for reuse up to 100 times. Our study has some limitations. The first and the most important limitation was the retrospective design of the study. Possibly because of the inadequate power of the study we did not observe significant differences between the groups for stone clearance rates and costs. Another limitation was our lack of knowledge regarding the stone compositions, which might have affected the surgical results.

\section{Conclusions}

Our study showed that both ultrasonic and laser lithotripsy were safe and effective stone fragmentation methods in miniperc. Laser lithotripsy seems to be less costly and more effective than ultrasonic lithotripsy during miniperc operations but larger numbers of patient series are required to further investigate these preliminary findings.

\section{AUtHOR CONTRIBUtions}

Concept - F.A.; Design - F.A.; Supervision - G.G., E.S., A.S.; Resource: E.S., E.K, F.O.; Materials - O.K., E.K., B.U.; Data Collection \&/or Processing - O.K., E.K., F.O.; Analysis\&/or Interpretation - O.K., E.S., A.S.; Literature Search - F.A., F.O, B.U.; Writing - F.A., B.U., G.G.; Critical Reviews - G.G., A.S.

\section{REFERENCES}

1. Türk C, Knoll T, Petrik A, et al. EAU guidelines on Urolithiazis, 2014 http://www.uroweb.org/guidelines/online-guidelines.

2. Helal M, Black T, Lockhart J, Figueroa TE. The Hickman peelaway sheath: alternative for pediatric percutaneous nephrolithotomy. J Endourol. 1997;11:171-2.

3. Jackman SV, Docimo SG, Cadeddu JA, et al. The "mini-perc" technique: a less invasive alternative to percutaneous nephrolithotomy. World J Urol. 1998;16:371-4.

4. Bader MJ, Gratzke C, Seitz M, et al. The "all-seeing needle": initial results of an optical puncture system confirming access in percutaneous nephrolithotomy. Eur Urol. 2011; 59:1054-9.

5. Desai MR, Sharma R, Mishra S, et al. Single-step percutaneous nephrolithotomy (microperc): the initial clinical report. J Urol. $2011 ; 186: 140-5$.

6. Mishra S, Sharma R, Garg C, et al. Prospective comparative study of miniperc and standard PNL for treatment of 1 to $2 \mathrm{~cm}$ size renal stone. BJU Int. 2011; 108:896-9.

7. Ganesamoni R, Sabnis RB, Mishra S, et al. Prospective Randomized Controlled Trial Comparing Laser Lithotripsy with Pneumatic Lithotripsy in Miniperc for Renal Calculi. J Endourol. 2013; 27:1444-9.

8. Pareek G, Armenakas NA, Fracchia JA. Hounsfield units on computerized tomography predict stone-free rates after extracorporeal shock wave lithotripsy. J Urol. 2003; 169:1679-81.

9. Kirac M, Bozkurt OF, Tunc L, et al. Comparison of retrograde 
intrarenal surgery and mini-percutaneous nephrolithotomy in management of lower-pole renal stones with a diameter of smaller than $15 \mathrm{~mm}$. Urolithiasis. 2013; 41:241-6.

10. Finley DS, Petersen J, Abdelshehid C, et al. Effect of holmium:YAG laser pulse width on lithotripsy retropulsion in vitro. J Endourol. 2005; 19:1041-4.

11. Spore SS, Teichman JM, Corbin NS, et al. Holmium: YAG lithotripsy: optimal power settings. J Endourol. 1999; 13:559-66.

12. Teichman JM, Vassar GJ, Bishoff JT and Bellman GC. Holmium:YAG lithotripsy yields smaller fragments than lithoclast, pulsed dye laser or electrohydraulic lithotripsy. J Urol. 1998; 159:17-23.

13. Begun FP. Modes of intracorporeal lithotripsy: ultrasound versus electrohydraulic lithotripsy versus laser lithotripsy. Semin Urol. 1994; 12:39-50.
14. Fuchs GJ. Ultrasonic lithotripsy in the ureter. Urol Clin North Am. 1988; 15:347-59.

15. Karakan T, Diri A, Hascicek AM, et al. Comparison of ultrasonic and pneumatic intracorporeal lithotripsy techniques during percutaneous nephrolithotomy. Scientific World Journal. 2013; 2013:604361.

16. Krambeck AE, Miller NL, Humphreys MR, et al. Randomized controlled, multicentre clinical trial comparing a dual-probe ultrasonic lithotrite with a single-probe lithotrite for percutaneous nephrolithotomy. BJU Int. 2011; 107:824-8.

17. Diri A, Resorlu B, Astarci M, et al. Tissue effects of intracorporeal lithotripsy techniques during percutaneous nephrolithotomy: comparison of pneumatic and ultrasonic lithotripters on rat bladder. Urol Res. 2012; 40:409-13.

\section{Correspondence}

Fatih Akbulut, MD (Corresponding Author)

drfakbulut@hotmail.com

Seyitnizam Mahallesi Yunus Emre Caddesi Merkez Park Yel Evleri A2 Blok Kat:1

Daire:3 Zeytinburnu, 34015 Istanbul,Turkey

Onur Kucuktopcu, MD

onurktp@hotmail.com

Emre Kandemir, MD

emrekandemir@gmail.com

Erkan Sonmezay, MD

drekans@gmail.com

Abdulmuttalip Simsek, MD

simsek76@yahoo.com

Burak Ucpinar, MD

drburakucpinar@gmail.com

Faruk Ozgor, MD

md.farukozgor@yahoo.com

Gokhan Gurbuz, MD

zafergokhangurbuz@yahoo.com

Haseki Training and Research Hospital, Department of Urology, Istanbul, Turkey 